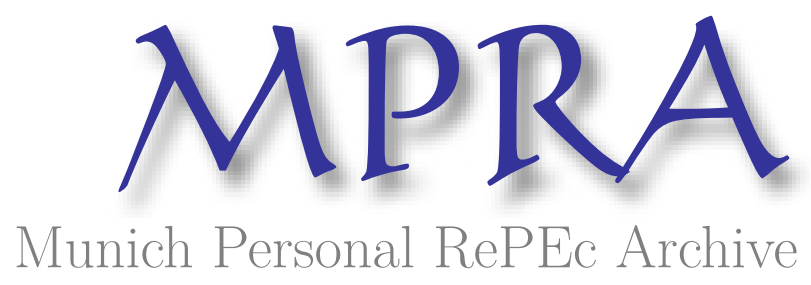

\title{
The world oil market, past and future
}

Chichilnisky, Graciela and Heal, Geoffrey

1984

Online at https://mpra.ub.uni-muenchen.de/8079/

MPRA Paper No. 8079, posted 04 Apr 2008 05:58 UTC 


\title{
The World Oil Market, Past and Future
}

\author{
Graciela Chichilnisky and Geoffrey Heal
}

\begin{abstract}
Oil price behavior has ehanged dramatically in the last twenty years. These changes can be explained rather simply in terms of the delayed responses of supply and demand to prices, and in terms of ehanges in the rade of discovery of regerves. This analysis can be tosed to forecast possible future developments.
\end{abstract}

CRLDE OIL PRICE trends have switched may times in the past, as shown in Chart 1. Prior to the early 1970s, the constant-dollar (and sometimes even the current-dollar) price of oil was drifting slowly and steadily downwards. Over this period. the oil market was seen by most commentators as being in a state of perpetual surplus, a state which was expected to continue. Then, in the curly 1970s, matters clearly changed. Note that although the big price rise that made OPEC famous happened n 1973, the change in the trend of prices in fact occursed before then: the price of crude oil started rising in 1970 , and by 1973 was increasing at historically unprecedented rates. Since 1973. constant-dollar oil prices have moved erratically: they have

Craciela Chichilnisky is Professor of Economics at Columbia Unitersity. She holuls. loctorates in Mathematics and in Economics from the Unicersity of California ut Berkeley, and taught pretiously at Herward and Berkeley. She has worked for OPEC, the United Nutions (UNITAR), the World Bank and the Banco Central de la Republica Argentina and is currently teaching international and mathematical economics. Geoffrey Heal is Professor of Economics at the Columbia Btsiness School; he previously taught at Combridge, Essex, Yale and Stanford. He ias worked for OPEC and for a number uf oil companies, and is currently uriting and teaching in the fields of international pconomics, resource economics and ecorismic theory. been typified by occasional sharp increases interspersed among periods of constancy or slight downward drift. The drop in current US dollar prices in 1983 introduced a new element.

In this article. we provide an explanation of this behavior of prices, and tentative forecasts of future developments.

\section{Before 1970}

Up to 1970 , the price of oil fell for two decades. Several factors contribute to an explanation-discoveries of large new deposits, negative real interest rates, expectations about price movements, and the role of the major oil companies.

Chart $2 \mathrm{~A}$ shows the evolution of proven reserves of crude oil from 1950 to 1970 . By 1970 , these stood at twice their level in 1960, in spite of the high levels of oil consumprion in the $1950 \mathrm{~s}$ and $1960 \mathrm{~s}$. This reflects a series of major discoveries. Over the period to 1970 , the balance between supply and demand was shifting, with supply rising faster than demand. This led to a downward pressure on prices.

\section{Price Psychology}

Another important factor is that price movements in many commodity markets can be self-reinforcing, at least over limited periods of time. The reason is that in these markets, a very important role is played by the expectations beld by traders about the prices that will rule in future periods. Producers have to decide whether to produce and sell now, or whether to delay until a future date. Obviously, they will be tempted to delay if in the interim they anticipate a significant rise in prices, so that by postponing their sale they can realize it capital gain. Conversely, they will sell now, rather than later, if they expect a significant drop in prices, for by selling now they avoid is capital toss. Traders expectations of how prices will move in the near future. are strongly influenced by their experience in the recent past: there is a tendency to extrapolate recent trends into the future, at least unless there is some obvious reason for circumstances to change. So a history of price increases will induce expectations of more of the same, and so will encourage sellers to hold their product off the market in anticipation of capital gains. This will tend to increase current prices. Conversely, a history of falling prices will tend to boost supply as sellers rush to avoid capital losses.

On the consumer side, exactly the opposite arguments apply. If prices are expected to rise, for example because they have been rising, then consumers clearly will buy sooner rather than later, raising demand and 
again leading to higher current prices. An expectation of price falls will have the opposite effect.

Putting together the consumer and producer sides of this story, it is clear that a period of falling prices can be self-reintorcing. It encourages producers to increase supply to avoid capital losses, and it encourages consumers to reduce demand and buy later: both of these tendencies put further downward pressure on prices. A symmetric argument applies to price increases: producers will hold off the market. and consumers will anticipate future needs, reinforcing the upward pressures.

\section{The Oil ,Majors' Role}

Finally, there is an important institutional factor, the role of the international oil companies. Most non-economists are fumiliar with the economist's concept of monopoly-a single or dominant seller of a good. Less well-known is the mirror-image concept of monopsony-a single or dominant buyer of a good. Munopsony power is the power of a single buyer to hold the price of a good down: he or she faces no competition for the good, the sellers have nowhere else to turn, and the price may be forced very low.

Prior to 1970 the major Western oil companies acted as a buyer cartel: they coordinated their crude oil buying strategy just as OPEC now coordinates its selling strategy. Because the oil market was a buyer's market anyway, and because the oil-producing countries were still largely politically subservient to the West, the oil companies were able to use their market power to control the price of crude oil, even to the extent of forcing cuts in the nominal price on the selling countries.

Clearly it is not difficult to explain why prices were falling prior to 1970 : supply was rising faster than demand, real interest rates were low or negative, expectations were of a continuing surplus and of downward pressure on prices, and the oil majors formed an active buying cartel which was unmatched by an equivalentlyactive selling cartel. In short, the world was a very different place then.

\section{0}

A well-established trend changed in the early 1970 s. As one might expect. a number of factors contributed to this. They included a sharp change in traders' perceptions of the supplydemand balance, leading to changes in expectations. and a change in the relative monopsony and monopoly powers of buyers and sellers respectively. There was also a transfer of control and ownership over major middle-eastern oil reserves. Once a new trend was established, the selfreinforcing rendencies already mentioned were there to continue it.

Return to Chart 2 (A\&B) or details of the supply-demand balance: the rate of discovery of major oil deposits has declined since the early $1970 \mathrm{~s}$, while for most of the 1970s consumption continued to grow, or at leust remained flat. By 1982, proven reserves of oil were only slightly greater than in 1970, in spite of the great increase in prices between 1970 and 1982, and the very extensive exploration and development activitics carried out in the interim. There werc few really major discoveries during this period, and much of the addition to reserves consisted of bringing into production known but previously uneconomic deposits of oil. Oil was no longer becoming more abundant, and began to get scarcer. Perhaps just as important, the world became very conscious of this fact. A series of widely-publicized studies drew the public's attention to the constraints that resource-scarcity could impose on economic growth. The earliest of these were the "Limits to Growth" and the "World Dynamic" studies. ${ }^{1}$ In retrospect they appear exaggerated and inaccurate; at the time, however, they had substantial impact, as they emphasized for the first time in the post-war era the fact that mineral resources could in principle be depleted. Both buyers and sellers became much more aware of the scarcity and strategic value that oil would come to have.

\section{Emergence of the US as Importer}

In addition to the changing balance between discoveries and consumption, and the growing awareness of possible shortages, another factor contributed to changing the tone of the market: this was the rapid passage of the US economy from oil self-sufficiency to substantial dependence on imports, a product of rising US oil consumption and falling US oil production. Chart 3 shows the growth of US oil imports in the late 1960 s and early $1970 \mathrm{~s}$. A substantial new customer entered the world oil market.

\section{Politics}

The balance between oil supply and oil demand in the international market changed in the early $1970 \mathrm{~s}$. This alone would have sufficed to change the trend of prices. However, during this period there were also important changes in Middle Eastern politics. and they acted to reinforce this newly-emerging trend. The region began to develop an increasing degree of political independence of the West, and to assert a growing measure of control over its own economic resources. Nasser's nationalization of the Suez canal in 1956 was a foretaste of this: Qadaffi's rise to power in Libya marked the first time that the trend really affected the oil market. The oil countries experienced a growing desire to control their own economic destinies, just as conditions in the oil market changed in such a way as to allow them to do so. Perhaps this was no coincidence: the desire may have been there all along, but suppressed as long as it looked unattainable.

This desire for greater economic independence manifested itsclf through measures designed to give host governments more control over production from wells on their territory, and a much larger share of the revenues from oil sales. In the late 1950 s and 1960 s, production and pricing decisions were controlled almost entirely by the major oil companies, with a very minor role for the governments of the host countries. Attempts to assert local control over oil fields, such as that of the Iranian Prime Minister Mossadeg to nationalize oil companies in Iran in 1948, provoked prompt governmental responses from the Western countries. The transfer of control over production and pricing decisions to the host countries in the late 1960 s and early 1970 s, led to a cut-back in production rates. The new controllers were more concerned than their predecessors to conserve the economies, resource base, and to assure a long-run supply of oil from their territories. This change 
was compounded by the fact that prior to the transfer of power to the local governments, many oil companies had even been producing at very high rates to remove as much oil as possible from the deposits while they were still under their control. There was thus a sharp reduction in the production of some OPEC members, reinforcing the other upward pressures on prices. The desire of the oil countries for greater economic independence was also expressed through a more aggressive role for OPEC: the major oil exporters realized that a common front and a coordinated pricing policy could greatly increase their bargaining power.

We now have a picture of a tightening oil market, switching from a buyer's to a seller's market, and sellers eager to get a better deal than they had before. The price trend switched, and the new trend reinforced itself by the processes we discussed before. In the early 1970s, oil ministers were often heard declaring that oil in the ground gave a better return than money in Western banks, meaning that the rate of price appreciation of oil gave them a strong incentive to delay selling and enjoy capital gains.

\section{3-1983}

\section{Demand Responses}

In the short-term, the demand for oil is insensitive to price. So the increase of 1973 had little immediate effect on demand. However, when it became clear that the new price levels would be sustained, and that oilpricing policies bad entered a new era, the higher prices set in motion a number of processes that have still not been completed:

development of more fuel-efficient vehicles and aircraft,

- development of more fuel-efficient industrial processes,

- and development of building and heating technologies oriented towards minimizing heating and cooling costs.

At the same time, the increased relative prices of energy-intensive activities began to shift consumer demand away from these and towards alternatives whose costs were less closely tied to the price of energy.
None of these factors affected the demand for oil much before the late 1970s: then their consequences began to be felt, leading to progressive reductions in the energy-intensity of the goods and services produced and consumed in the industrial countries. A much quoted statistic on this subject is that the amount of energy used in producing $\$ 1000$-worth of constant-dollar GNP in the US fell by $38.9 \%$ from 1973 to 1983 . This was a result of switching to more energy-efficient technologies, and of demand patterns changing away from energy-intensive products and services. Most of this striking drop in energy use occurred in the period 1979-83.

\section{Supply Responses}

The 1973 price increase also set in motion important long-run forces on the supply side. In particular, it initiated a major rise in non-OPEC oil production, as Chart 4 shows. The mechanism by which this occurred was very straight-forward: at higher prices, the rewards to oil exploration and development were greatly increased, leading to a dramatic rise in exploration activities. At the same time, known oil deposits whose extraction costs were too high for them to yield a profit at $\$ 1.50$ per barrel, became quite attractive propositions at $\$ 12$ per barrel. So new deposits were discovered and brought into production (as for example in Mexico and the North Sea), and known but previously sub-marginal deposits were brought into production. All of this takes time. It may be five years from the discovery of a new oil field to the time when it starts producing, and indeed if the terrain is difficult, as in the North Sea or in Alaska, the delays can be longer.

\section{The Market Turns}

So the 1973 price increase had little immediate effect on demand, but set in motion forces which a decade later would lead to a squeeze in the market-a gradual build-up of non-OPEC supply, and a gradual decline in demand. It is these events that were primarily responsible for the downward pressure on prices in the early 1980 s and not, as is sometimes argued, the recession in the industrial countries. This is easily appreciated by some simple calculations. Take the income elasticity of demand for oil to be 0.8 , as suggested by a range of empirical studies. At the worst point of the OECD recession, levels of national income declined less than $5 \%$ from their previous peaks. If the income elasticity of demand is 0.8 , this would lead to a drop in demand for oil of at most $4 \%$.

Estimating the impact of higher prices requires a little more patience. In 1973 crude oil prices rose $400 \%$, from $\$ 3$ per barrel to $\$ 12$ per barrel. This contributed between 20 cents and 25 cents extra to the cost of a gallon of petroleum products, leading to an increase in their consumer prices of between $40 \%$ and $50 \%$. For simplicity we will work with the $50 \%$ figure. Table 1 shows the drops in demand that would result from a $50 \%$ price rise, for various values of the price elasticity of demand. A short-run elasticity of about -0.2 would imply that the impact effect of the 1973 price rise was a demand drop of about $10 \%$. If the long-run price elasticity is of the order of -0.5 , then in the long run there would be a demand reduction of about $25 \%$. If the long-run elasticity were of the order of -1.0 , then we would expect the 1973 price to lead to a drop in demand of about $50 \%$. In fact 1983 might be too early for the full effects of the 1973 price rise to be felt. If two-thirds of this effect had been felt by 1983 , this would account for a demand drop of either $17 \%$ or $35 \%$, depending on the elasticity figure chosen: this is clearly much greater than the roughly $4 \%$ attributable to the OECD recession. In fact to this $17 \%$ or $35 \%$ due to the 1973 price rise, we must add the short-run consequences of the $1978-9$ price rise. Then higher prices can easily account for a demand drop of over $20 \%$ from its peak, and quite possibly nearer $40 \%$.

\section{Oil and Exchange Rates}

The decade 1973-83 was one in which the world began to adjust to higher oil prices. The adjustment was not completed: some of it will still be under way at the end of the century. Demand dropped by $20 \%$ or more because of higher prices, and by $5 \%$ because of the recession in 
TABLE 1

Relationship of Demand to Price Elasticity Demand for a $50 \%$ Price Rise. PED $\%$ Drop in Demand

\begin{tabular}{lr}
-0.1 & $5 \%$ \\
-0.2 & $10 \%$ \\
-0.3 & $15 \%$ \\
-0.4 & $20 \%$ \\
-0.5 & $25 \%$ \\
-0.6 & $30 \%$ \\
-0.7 & $35 \%$ \\
-0.8 & $40 \%$ \\
-1.0 & $50 \%$ \\
\hline
\end{tabular}

industrial countries. Expansion of non-OPEC production capacity contributed an extra $10 \%$ to the world's crude-oil capacity. Not surprisingly, there was a strong downward pressure on prices, and major production cutbacks by OPEC were needed to prevent more than a $\$ 4$ per barrel decline in the current US\$ price of crude oil. It should be noted that this $\$ 4$ drop in the US\$ price in 1983 did not lead to equal drops in oil prices in other currencies. It occurred during a period of rising exchange rates between the dollar and the currencies of other industrial countries, so that in European currencies or in Japanese yen the price of crude oil stayed constant or even rose slightly in 1983 . Nevertheless the drop in the US\$ price would have raised demand in the US, albeit by rather little.

\section{The Role of OPEC}

One final remark is in order on the 1973-83 decade in the oil market. Towards the end of this decade, as we have seen, the demand for OPEC oil fell substantially. Total demand declined, and non-OPEC production rose. There are of course two ways in which a producer can respond to a decline in demand relative to supplyby cutting back output, or by reducing price. As the demand for oil is very price inelastic, at least in the short run, OPEC unquestionably stood to lose less in terms of current revenue by reducing output to match the lower demand, than by reducing price enough to raise demand back to their full-capacity output level. To understand this, consider the following numbers. Suppose that at present prices, the demand for OPEC oil has fallen $20 \%$, and that the short-run price elasticity of demand for oil is -0.3 . Then if OPEC simply cuts back output by $20 \%$, keeping the price constant, its revenue falls by $20 \%$. Suppose on the other hand that it tried to boost demand $20 \%$ back to the original level by cutting price. Then a price reduction of in excess of $60 \%$ would be needed, leading of course to a revenue drop of the same size. So by cutting output much more than price, OPEC clearly made the right choice of response to the changed market conditions.

Many analysts have been concerned with OPEC's role in the world oil market, and the extent to which it can be said to exercise market power. The ability to ensure that a demand reduction was met by a cut in production rather than in prices, is in fact probably the most important indication to date of OPEC's power, and of what differentiates the oil market from other commodity markets. Without a cartel framework to negotiate reduced production quotas and to provide some assurance that they would be observed, the excess supply would almost certainly have led to price rather than output reductions. In fact this is just what happened with other commodities. In the early $1970 \mathrm{~s}$, their prices moved very much in parallel with oil, rising sharply. However, as demand fell because of recession and substitution, their production levels remained constant and their prices fell sharply, reaching historical lows in real terms by the early 1980s. Chart 5 shows the price movements for several other primary commodities. That oil avoided their fate in the $1980 \mathrm{~s}$, although it had shared it during similar periods in the $1950 \mathrm{~s}$ and $1960 \mathrm{~s}$, is a measure of OPEC's impact on the oil market.

\section{Onward}

How is the oil market likely to develop? In the medium term-say the next decade-it seems safe to predict a continuation of the trends just described. Non-OPEC production will remain high. Demand will continue to decline as a long-run consequence of the 1973 price increase, with a drop of at least $10 \%$ the next five years. The 1978-79 increase will also have an effect-this raised retail prices by about $30 \%$, and so might contribute at least a further $15 \%$ in round num- bers to the drop in demand, taking effect over the next ten years. The only offsets to these downward pressures will come from expansion in the oil-consuming countries, and from the effect of the slight price reduction in 1983 on demand. Economic expansion in the industrial countries at $2 \%$ per annum, maintained for ten years, could add a little less than $20 \%$ to annual demand by the tenth year. The $\$ 5$ per barrel drop in the price of oil in 1983 is not likely to add more than $3 \%$ or $4 \%$ to demand, even in the long run.

This picture that emerges over the next decade is thus that past price increases will continue to feed through to demand, leading to a drop of about $25 \%$. Industrial expansion of $2 \%$ p.a. and the long-run effects of the 1983 price fall would not quite offset this. But the difference could easily be made up by a slight reduction in non-OPEC production-for example as the North Sea fields pass their production perks - or by rapid industrial expansion in some of the middleincome developing countries. Alternatively, more rapid expansion of the industrial countries could lead to a net increase in demand. This would not, however, produce upward pressure on prices, because of the large margin of unused capacity in OPEC.

The expected outcome is thus essentially a continuation of the present. A forecast of this type, however, can easily be upset. Continuation of the present requires that OPEC members keep their production levels substantially below their theoretical maximum. Table 2 lists the present outputs of OPEC members and their theoretical maximum output levels. For countries which are very short of foreign exchange, the temptation to raise production will be very great. If one country raised output, and this move were not followed by others, then the market price would move little and the expanding country would earn more foreign exchange. In fact such a move would almost certainly be followed by other countries, and the resulting extra output would initiate another round of price reductions. In the end, all oil-producers would be worse off in terms of foreign exchange. At the time of writing, it is too early to tell whether OPEC will succeed in holding the line on produc- 
tion ceilings for a substantial number of years. Obviously, they would be aided in this by a relatively rapid economic expansion of the industrial countries, which would take some of the downward pressure off prices.

If one looks further ahead than the next decade, a rather different picture emerges. By the mid 1990s, we will have seen most of the consequences of the price increases of the $1970 \mathrm{~s}$. Demand patterns will have stabilized with the continuing downward pressure removed. On the supply side, non-OPEC production will be past its peak. Production from the North Sea and Alaska will be declining, and it is possible that the same will be true of Mexico and the USSR. Some OPEC members will also have declining output levels-for example Iran and Algeria. So demand will be stabilizing just as production again begins to concentrate in OPEC, and indeed in those OPEC members in the
Persian Gulf. In principle this could set the scene for a period of rising prices, though such a forecast is very tentative-a lot of factors could intervene.

One would be a major break through in the field of "backstop technologies." For example, the development of a process for producing crude oil from unconventional oil deposits (shale, tar sands) conveniently and in the range of $\$ 30-\$ 40$ ( 1983 prices), would certainly put a long-run ceiling on prices. Currently this looks unlikely, but it is a possibility. One might also speculate about the possibility of finding really major new oil fields, for example in China or elsewhere in the far east. To have a major effect on prices they would have to be very large-comparable to some Middle Eastern fields-and again this seems most unlikely, but cannot be ruled out.

There could also be unexpected developments that exerted an upward pressure on prices. One such eventuality would be the complete abandonment of nuclear power programs in industrial countries. Another would be a substantial reduction in the mining and combustion of coal. Large-scale coal mining has harmful environmental effects and leads to major ecological disruption. It is conceivable that environmental concerns could restrict the rapidly-growing use of coal, shifting back to oil some of the demand that has transferred to coal since 1973. Finally, a rather different possibility is a major political disruption in the Middle East.

Making predictions in the oil market remains, as ever, a risky business. What we have set out above is a benchmark case, showing how matters are likely to develop if there are no major surprises. A few possible surprises have been mentioned, but there must surely be many that have not!

\section{NOTE}

1. The references are to J. W. Forrester, Worid Dynamics, Wright Allen Press, 1971 and D. H. Meadows et al., The Limits to Growsh. Universe Books, New York and The Limits to Growsh, Universe Books, N later and more balanced yiew of the same issues is in $G$. Chichilnisky, A. Hererra, H. Scolnick et al., Catastrophe or New Society, 1976, International Development Research Centre, Otlawa, Canada.

CHART 1. Crude oil prices in nominal terms $(1970=100)$ and deflated by the U.S. G.D.P. deflator.

30

20

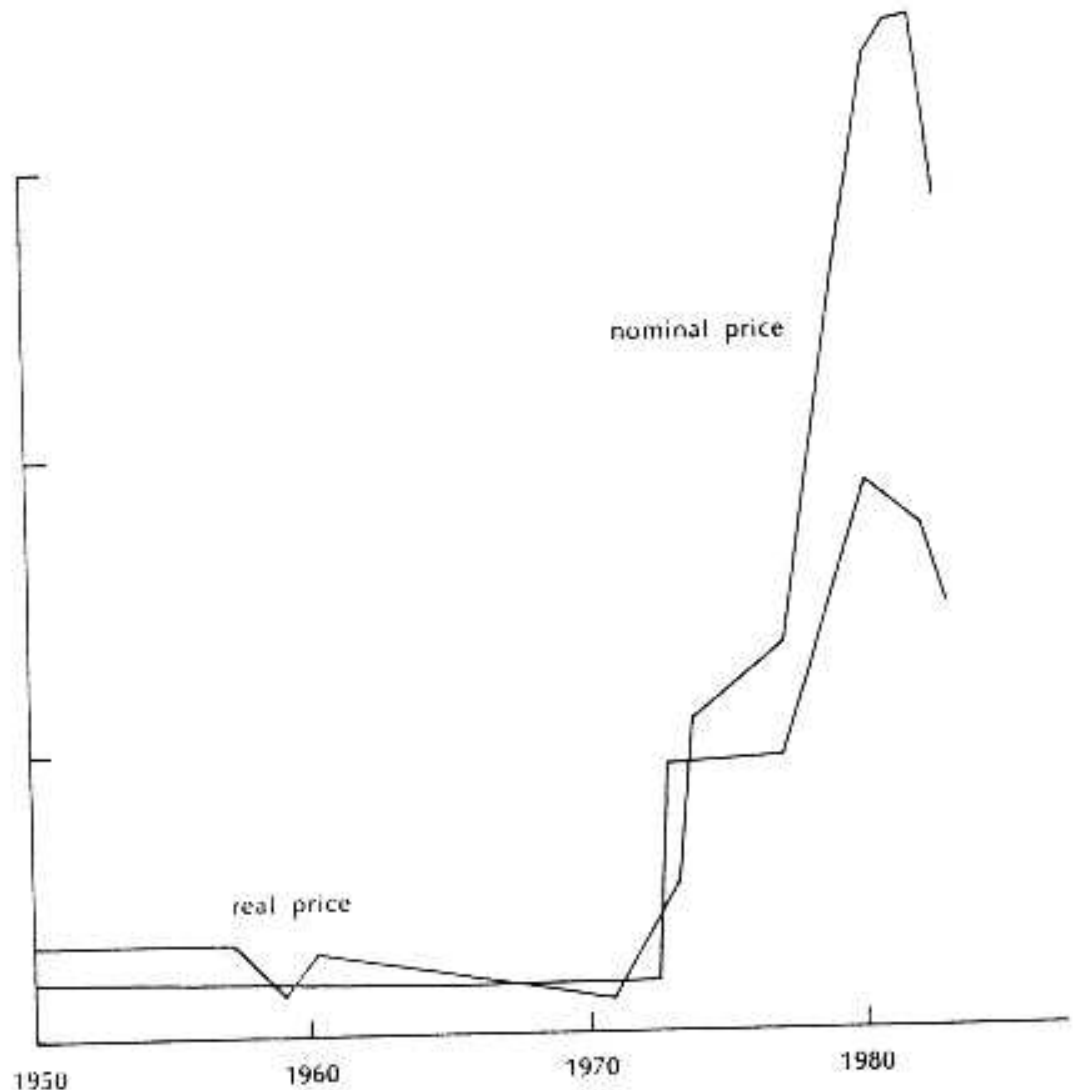

1951

Source:- Trade and Development Report, 1982, and O.P.E.C. Annual Statistical Bulletins. 
CHART 2A Estimated world proven reserves of crude oil, annually as of January 1st., thousands of barrels, and energy consumption in O.E.C.D. countries.

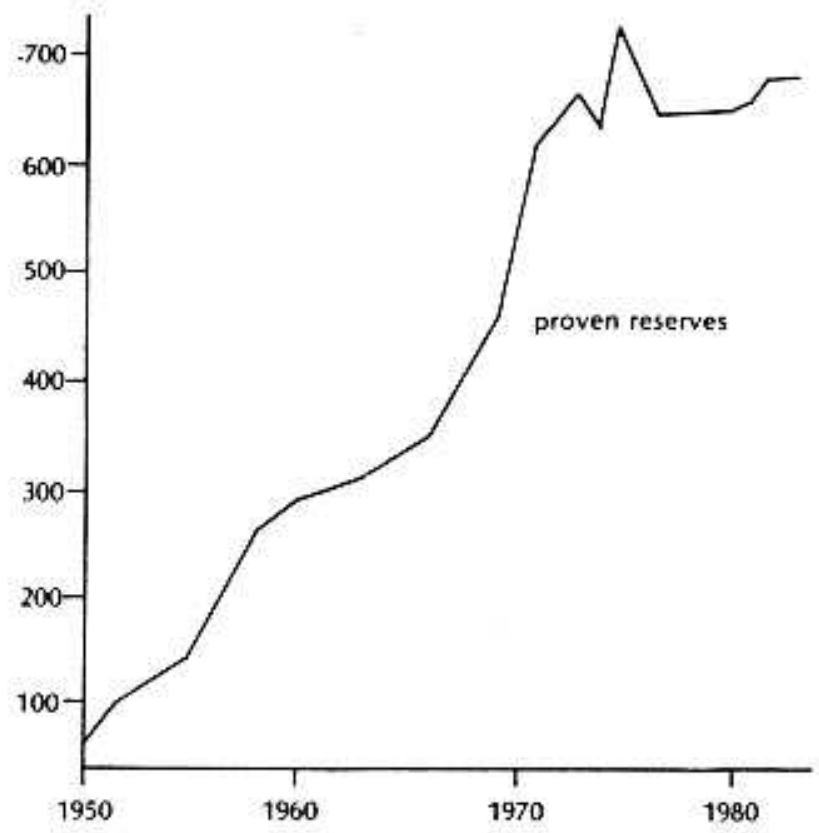

Source: Basic Petroleum Data Book, 1983, and I.E.A., Energy Balances of the O.E.C.D. Countries, various issues.

CHART 2B ENERGY CONSUMPTION IN INDUSTRY IN OECD COUNTRIES, 1960-1980

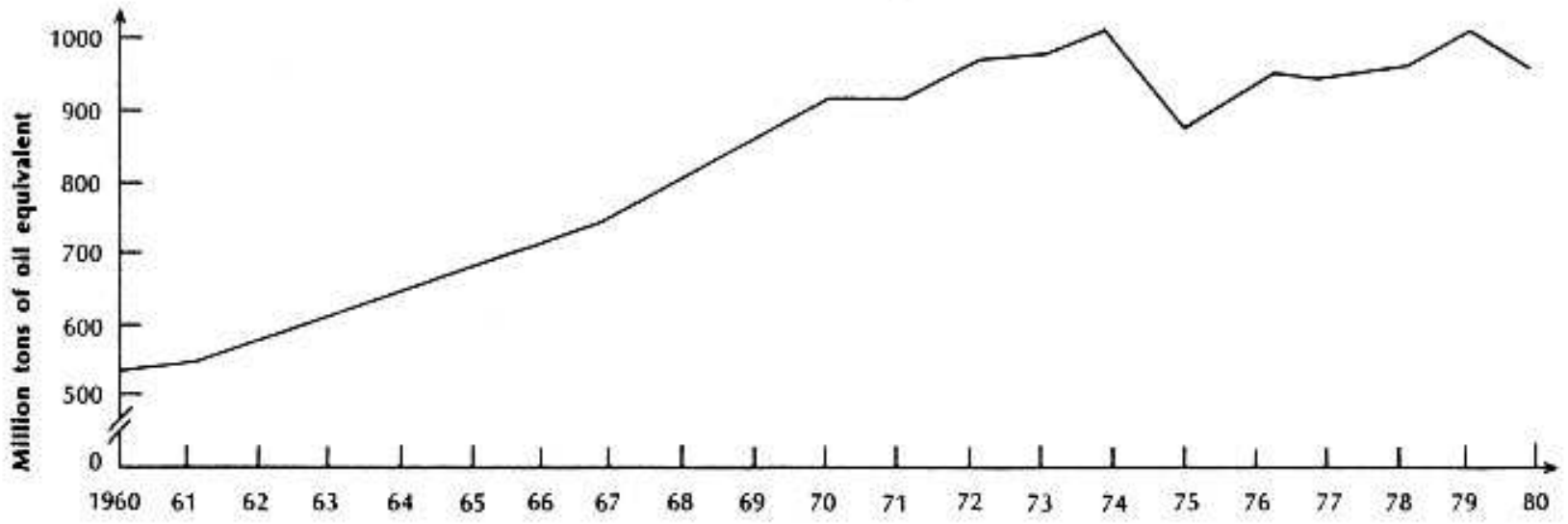

Source: IEA, Energy balances of OECD countries (various issues) 
